\title{
Low temperature processing of solution-derived ceria deposits on flat surfaces of 3D-printed polyamide
}

\author{
S. Morales-Planas ${ }^{\mathrm{a}}$, A. Calleja ${ }^{\mathrm{b}, *}$, V.R. Vlad ${ }^{\mathrm{b}}$, J. Oró-Soléc ${ }^{\mathrm{c}}$, J. Minguella-Canela $^{\mathrm{d}}$, J. Farjas \\ ${ }^{a}$ Fluidra S.A., C/Ametllers, 6, 08213, Polinyà, Barcelona, Spain \\ ${ }^{\mathrm{b}}$ Oxolutia S.L., Avda. Castell de Barberà 26, Tallers 13, Nau 1, 08210 Barberà del Vallès, Barcelona, Spain \\ ${ }^{\mathrm{c}}$ ICMAB-CSIC, C./Til.lers, Campus de la UAB, 08193, Bellaterra, Barcelona, Spain \\ ${ }^{\mathrm{d}}$ Universitat Politècnica de Catalunya, Avda. Diagonal, 647, 08028 Barcelona, Spain \\ e GRMT, Dept. of Physics, University of Girona, Campus Montilivi, Edif. PII, E17071 Girona, Spain
}

A R T I C L E I N F O

\section{Keywords:}

Ceria

Metalorganic decomposition

3D-printing

Polyamide

Functionalization

\begin{abstract}
A B S T R A C T
Doped ceria deposits have been prepared on 3D-printed polyamide-12 components starting from inkjet-compatible solutions in an attempt to functionalize the surface of the plastic part, followed by a low temperature decomposition process at $160^{\circ} \mathrm{C}$ in air. The non-continuous deposits were characterized by simultaneous thermogravimetric analysis, differential scanning calorimetry and evolved gas analysis, X-ray diffraction, X-ray photoelectron spectroscopy, scanning electron microscopy with energy dispersive X-ray spectroscopy, transmission electron microscopy and electron diffraction. After thermal treatment, the deposits are still clearly visible at the surface of the polymer. However, no crystallinity of the ceria is observed, in contrast to identical low temperature processing on inert substrates such as glass where nanoparticle ceria aggregates were produced. This is tentatively explained by the chemically-reducing character of the polyamide, and in particular to $\mathrm{CO}$ and hydrocarbon gases released during the heating process, which would continuously induce the reduction of $\mathrm{Ce}^{4+}$ to $\mathrm{Ce}^{3+}$ at the low temperature of $160{ }^{\circ} \mathrm{C}$, influencing the non-detection of crystalline ceria.
\end{abstract}

\section{Introduction}

$\mathrm{CeO}_{2}$ is a well-known multipurpose functional oxide applied in 3way catalysts, oxygen conductor for solid-oxide fuel cells [1], gas sensors [2], UV-protecting coatings [3,4], anticorrosion in metals [5], abrasive in mechano-chemical polishing [6], new homogeneous-like heterogeneous catalysts [7] or as buffer layer for heteroepitaxial arquitectures [8]. Furthermore, doping with other metals such as Gd, Sm, $\mathrm{Zr}$, etc. is a common strategy to increase oxygen mobility [9].

On the other hand, 3D printing of plastic components is envisioned as an effective manufacturing technique able to reduce logistic and stock management deriving in a net cost reduction in the sector of spare parts, for instance. Many advancements have been seen in the last years in the different technical methods available. Among these, the Multi Jet Fusion (MJF) process developed is outstanding by its increased speed and accuracy [10,11].

In addition, procedures for cost-effective surface modification of 3Dprinted parts is being explored for increasing performance, aesthetic appearance or functionalization. In particular, deposition of functional oxides such as ceria seems therefore interesting for water applications because water decontamination can be achieved [12,13]. However, the relatively high temperatures and long annealing times required to consolidate oxides compared to typical technical polymers with low glass-transition temperatures render this as a difficult task. Related to this, the current trend to overcome this difficulty is the use of other techniques for fast sintering, such as photonic curing or microwave radiation [14].

Alternatively, a low temperature process starting from inks has been put forward by Roura et al. [15] which is compatible with the use of thermally-labile substrates, where full decomposition of ceria metalorganic salts was demonstrated at temperatures as low as $160^{\circ} \mathrm{C}$. This approach is also amenable to inkjet printing, a digital manufacturing process when ink formulation is adapted.

Making use of this advancement, we study the deposition of ceria on 3D-printed polyamide in this work, which can be considered as a complex technical substrate which poses new challenges. Ceria deposits from precursor metalorganic inks compatible with inkjet printing have been prepared following low temperature processing for effecting the metalorganic decomposition. Characterization tools such as X-ray diffraction (XRD), scanning electron microscopy with energy dispersive X-

\footnotetext{
* Corresponding author at: Avda. Castell de Barberà 26, Tallers 13, Nau 1, 08210 Barberà del Vallès, Spain.

E-mail address: acalleja@oxolutia.com (A. Calleja).
} 
ray spectroscopy (SEM/EDX), X-ray photoelectron spectroscopy (XPS), transmission electron microscopy (TEM) and electron diffraction have been employed to gain insight into the produced materials.

\section{Experimental details}

\subsection{Preparation of the precursor ink}

A precursor ink for $\mathrm{Zr}$-doped ceria with chemical formula $\mathrm{Ce}_{0.9} \mathrm{Zr}_{0.1} \mathrm{O}_{2-\mathrm{x}}$ (CZO) was prepared by weighting stoichiometric amounts of zirconium pentadionate or $\mathrm{Zr}\left(\mathrm{CH}_{3} \mathrm{COCHCOCH}_{3}\right)_{4}$ (SigmaAldrich, 99.9\%) and cerium (III) acetylacetonate hydrate or Ce $\left(\mathrm{CH}_{3} \mathrm{COCHCOCH}_{3}\right)_{3} \cdot \mathrm{xH}_{2} \mathrm{O}$ (Alfa Aesar, 99.9\%). They have been dissolved in propionic acid (Sigma-Aldrich, 99.5\%) and 1-butanol (SigmaAldrich, 99.8\%). A 5\% $v / \mathrm{v}$ of diethanolamine (Sigma-Aldrich) was also added. After stirring, the mixture was passed through a $0.2-\mu \mathrm{m}$ filter. The total metal concentration of the final yellowish solution was $0.25 \mathrm{M}$.

\subsection{Substrates}

Thermoplastic polyamide- 12 with formula $\left[(\mathrm{CH} 2)_{11} \mathrm{CONH}\right]_{\mathrm{n}}(\mathrm{PA} 12$ for short) is the main constituent of the 3D-printed parts by the MJF process. Flat substrates are prepared from polished 3D-printed pieces cut parallel to the XY printing layer, which are afterwards gently polished to avoid damage to the polymer. Inert (100)-oriented $\mathrm{LaAlO}_{3}$ (LAO) polished single crystals were used for the thermogravimetric and differential thermal analysis (TGA/DSC) of the precursor ink. Also, flat glass slides were employed for obtaining larger amounts of powders by drop casting.

\subsection{Deposition}

The CZO ink is then deposited on the PA12 substrates by spincoating at $6000 \mathrm{rpm}$ and an acceleration time of $2 \mathrm{~s}$ with an estimated thickness of $20 \mathrm{~nm}$. The samples were further subjected to heating in a furnace with forced air circulation at different temperatures of 160 and $175^{\circ} \mathrm{C}$ at different times up to 6 days. Around $1 \mathrm{ml}$ of CZO ink was also poured on watch glasses and thermally treated for comparison purposes.

\subsection{Characterization tools}

The morphology of the films after growth was checked by optical microscopy. Capillary XRD patterns have been acquired with a Bruker D8 A25 equipment with Mo-Ka radiation $(\lambda=0.71073 \AA)$ while another Bruker D8 in General Area Detector Diffraction System configuration (GADDS) with Cu-Ka $(\lambda=1.5418 \AA)$ was used for the coatings.

XPS measurements were performed at room temperature with a SPECS PHOIBOS 150 hemispherical analyzer (SPECS GmbH, Berlin, Germany) in a base pressure of $5 \cdot 10^{-8} \mathrm{~Pa}$ using monochromatic $\mathrm{Al} \mathrm{K \alpha}$ radiation $(1486.74 \mathrm{eV})$ as excitation source with a pass energy of $10 \mathrm{eV}$ and step size of $0.05 \mathrm{eV}$ for the high resolution spectra and $30 \mathrm{eV}$ and $1 \mathrm{eV}$, respectively, for the survey spectra. To compensate charging effects a flood gun was used and all spectra were calibrated with respect to the C1s peak at $284.9 \mathrm{eV}$.

SEM of the deposited surfaces was carried out with a high resolution FEI Quanta 200 FEG system. Chemical analysis of the samples has been investigated by EDX coupled to the SEM at $20 \mathrm{kV}$ and $6.57 \cdot 10^{-4} \mathrm{~Pa}$.

Simultaneous TGA/DSC were performed with a TGA/DSC1 thermobalance from Mettler Toledo. Since it has been stated than films tend to decompose differently than powders $[16,17]$, experiments have been performed directly on films. No pans were used; substrates were placed directly on the pan holder. A flow of $40 \mathrm{ml} / \mathrm{min}$ of synthetic air was set inside the thermobalance. TGA/DSC measurements were corrected by subtracting an experiment performed under identical conditions but with no sample to compensate the buoyancy as well as systematic deviations of the apparatus. Simultaneous Fourier-transform infrared (FTIR) evolved gas analysis (EGA) was performed with a Bruker model ALPHA spectrometer coupled to a gas cell (Transmission model); a steel tube kept at $200{ }^{\circ} \mathrm{C}$ was used to connect the thermobalance to the gas cell. Since the sensibility of TA measurements depends on the sample mass TGA/DSC experiments have been done in $1.6 \mathrm{mg}$ samples that correspond to a final CZO film of $1 \mu \mathrm{m}$, TGA/DSC/EGA have been performed on $16 \mathrm{mg}$ mass films that results in $10 \mu \mathrm{m}$ CZO films. Note that the actual thicknesses of the CZO films are around $50 \mathrm{~nm}$; i.e., films analyzed by TGA are much thicker.

Ex-situ IR of solid samples were collected using an attenuated total reflection (ATR) module (model Platinum ATR) connected to the same ALPHA spectrometer from Bruker. The spectra have been acquired both on PA12 substrates and on LAO as a model system.

A JEOL 1210 microscope operating at $120 \mathrm{kV}$ was used for the TEM and electron diffraction analysis. The specimen for electron microscopy was prepared depositing the powders on a carbon coated film supported on a copper grid.

\section{Results and discussion}

\subsection{Characterization of the as-received PA12 substrates}

An optical image of the 3D-printed PA12 substrate is shown in Fig. 1a, Some randomly-distributed pores between 20 and $200 \mu \mathrm{m}$ are
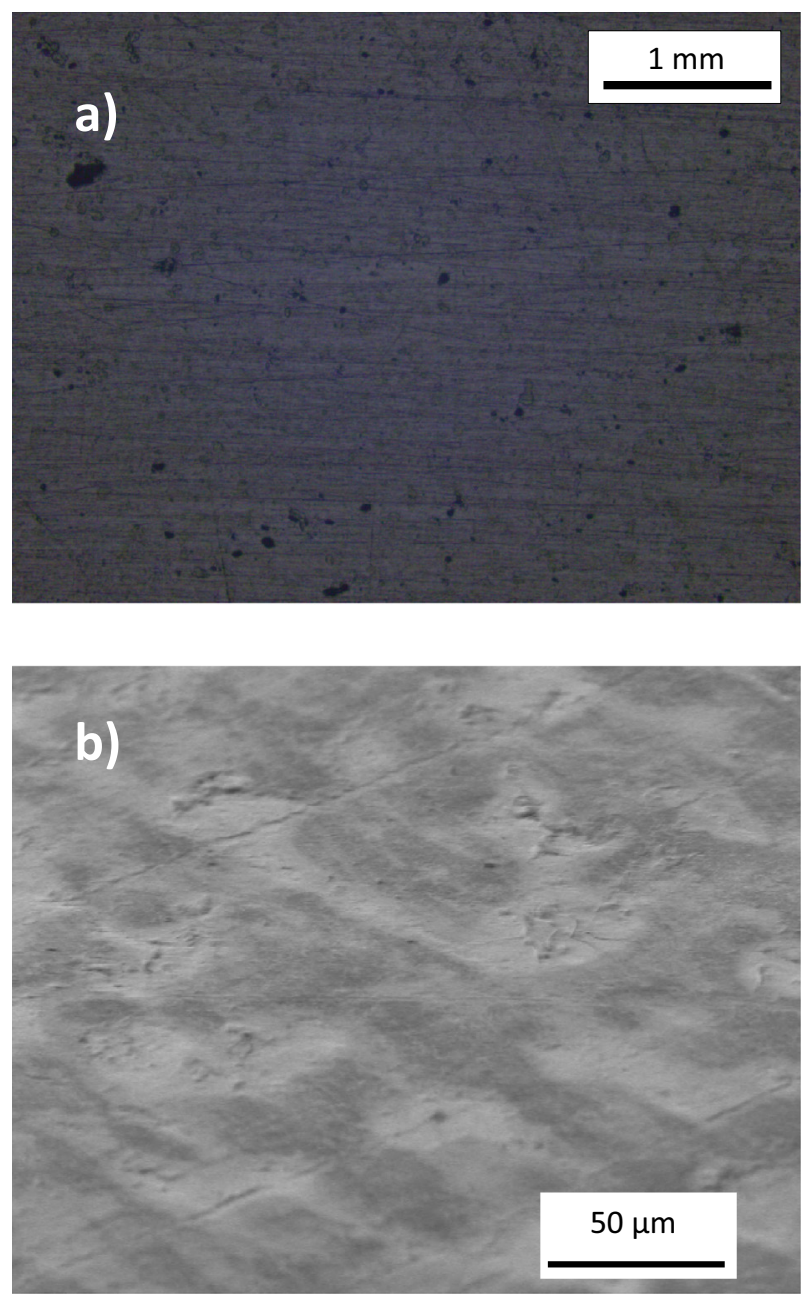

Fig. 1. a) 3D-printed PA12 substrate as observed by a) optical microscopy and b) SEM. 



Fig. 2. a) TGA/DSC plot for the pristine PA12 at $10{ }^{\circ} \mathrm{C} / \mathrm{min}$ in synthetic air, showing an onset temperature for melting of $169^{\circ} \mathrm{C}$. b) TGA of the CZO precursor ink deposited on $10 \times 10 \mathrm{~mm}^{2} \mathrm{LAO}$ at $10^{\circ} \mathrm{C} / \mathrm{min}$ in synthetic air. Two different films are tested: a very thick film $(16 \mathrm{mg})$ and a ten times thinner film (1.6 mg).

observed in the polymer [11] together with scratches due to the polishing that are difficult to remove completely. A tilted SEM micrograph of the PA12 can be found in Fig. 1b, in which the morphology of the 3Dprinted surface can be distinguished, consisting of sintered PA12 granules.

Separate TGA/DSC analysis of both the substrate and the ink were then undertaken to investigate compatible thermal treatments that could lead to thermal decomposition while retaining the mechanical stability of the polymeric substrate.

The TGA/DSC curves for the PA12 are shown in Fig. 2a. The plastic substrate starts to slightly decompose from $100{ }^{\circ} \mathrm{C}$. From $300{ }^{\circ} \mathrm{C}$ approximately, the polymer severely decomposes in at least two steps happening at intervals of $300-350^{\circ} \mathrm{C}$ and $350-390^{\circ} \mathrm{C}$ approx.

The simultaneous DSC curve first presents an endothermic peak starting at $169^{\circ} \mathrm{C}$ and ending at $196^{\circ} \mathrm{C}$ accounting for the melting of the polymer. In fact, experimental observation of the deformation of the pieces treated above $180^{\circ} \mathrm{C}$ would be a consequence of such melting. After that, three exothermic decomposition events centered at $350^{\circ} \mathrm{C}$, $387^{\circ} \mathrm{C}$ and above $400^{\circ} \mathrm{C}$ appear which are attributed to oxidative processes.

This is consistent with thermogravimetric studies reported in the literature for polyamide [18-20]. $\mathrm{H}_{2} \mathrm{O}$ was demonstrated to be the main gas being evolved at temperatures around $100{ }^{\circ} \mathrm{C}$, with release of secondary gases such as $\mathrm{CO}_{2}$, residual solvents such as ethanol, $\mathrm{CO}$ and hydrocarbons. The simultaneous formation of $\mathrm{CO}$ and hydrocarbons have been proposed to originate from internal cleavage of amide groups [18]. Above $300^{\circ} \mathrm{C}$ approximately, the organic backbone is severely scissioned in an oxidative degradation process in air [19].

On the other hand, the precursor ink was also analyzed on the inert substrate LAO, as can be seen in Fig. 2 b. Basically, the decomposition to CZO takes place in two steps. First, between 100 and $250{ }^{\circ} \mathrm{C}$ and then between 250 and $375{ }^{\circ} \mathrm{C}$, ending up at constant weight with the residue consisting of zirconium-doped cerium oxide. Note that in solid-gas reactions, the reaction rate is frequently limited by the diffusion of one of the volatiles species, thus, the thinner the film the faster the decomposition. In Fig. $2 \mathrm{~b}$ we have plotted the evolution of two films deposited in a $10 \times 10 \mathrm{~mm}^{2}$ LAO substrate with different masses; the $16 \mathrm{mg}$ mass film is ten times thicker than the $1.6 \mathrm{mg}$ film. One can verify that the first decomposition stage for the thin film is complete at $125^{\circ} \mathrm{C}$, i.e., more than $100^{\circ} \mathrm{C}$ below the thicker film. CZO films are actually much thinner, therefore they may decompose at temperatures significantly lower than those observed in Fig. 2.b, as it has already been stated in the decomposition of cerium propionate [15]. Simultaneous EGA has been performed to identify the evolved volatiles. The evolution of these volatiles is shown in Fig. 3. Propionic acid is released, reaching a maximum at $271{ }^{\circ} \mathrm{C}$. This is in accordance to the fact that propionic acid is the main product of decomposition of metal propionates in air whereas at higher temperatures radicalary reactions result in the formation of 3-pentanone [21]. Finally, at higher temperatures, around $350{ }^{\circ} \mathrm{C}$, the oxidation of the organic fragments is related to the increasing amounts of $\mathrm{CO}_{2}$ and $\mathrm{CO}$.

In Fig. 4a, FT-IR spectra of as-deposited film on PA12 and after heating at $10 \mathrm{~K} / \mathrm{min}$ up to $160^{\circ} \mathrm{C}$ in air in the TGA/DSC apparatus are compared. The large difference is clear in the region below $2000 \mathrm{~cm}^{-1}$. To ascertain the chemical nature of the coating after the heating, its spectrum is compared with sodium propionate [22], which is shown in Fig. 4b. The matching between both spectra can be clearly seen, revealing that cerium propionate is the main product after the heating on PA12.

The following step was to investigate if FT-IR could be used for tracking the decomposition of the precursor on polyamide. In Fig. 5, the FT-IR spectra of three different ceria deposits at varying temperature programs are presented: a) Heating to $160^{\circ} \mathrm{C}$ at $10^{\circ} \mathrm{C} / \mathrm{min}$, heating to $175^{\circ} \mathrm{C}$ at $5{ }^{\circ} \mathrm{C} / \mathrm{min}$ and keeping at $160^{\circ} \mathrm{C}$ for $24 \mathrm{~h}$, all of them in air. The first two treatments were performed in the TGA/DSC apparatus and correspond to films of thickness 1 and $2 \mu \mathrm{m}$, respectively, while the

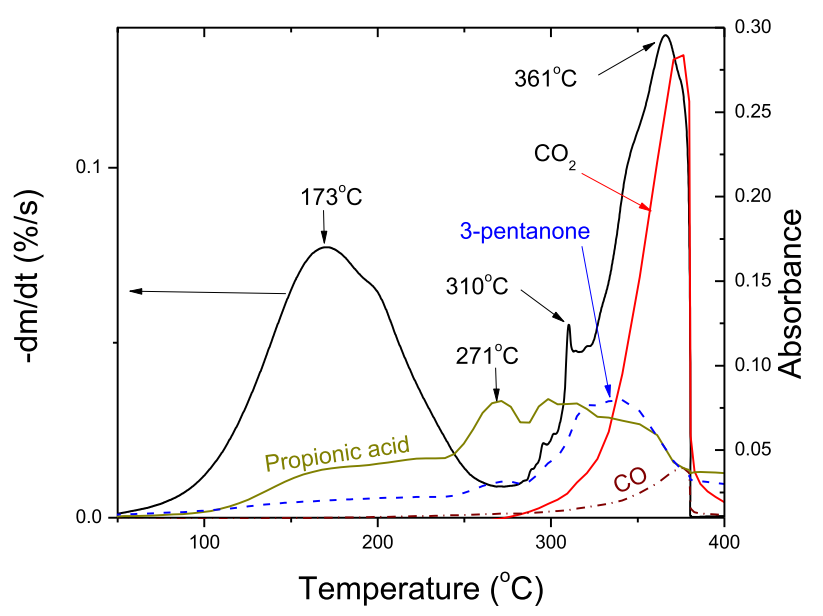

Fig. 3. In-situ EGA of the TGA shown in Fig. 2.b (16 mg film); evolution of the absorbance peak intensity of characteristic frequencies of the observed volatiles: $2360 \mathrm{~cm}^{-1}\left(\mathrm{CO}_{2}\right), 2188 \mathrm{~cm}^{-1}$ (CO), $1793 \mathrm{~cm}^{-1}$ (propionic acid) and $1732 \mathrm{~cm}^{-1}$ (3-pentanone). For the sake of comparison, the mass loss rate, $-\mathrm{dm} / \mathrm{dt}$, is included and the absorbance of $\mathrm{CO}_{2}$ has been divided by a factor 8 . 

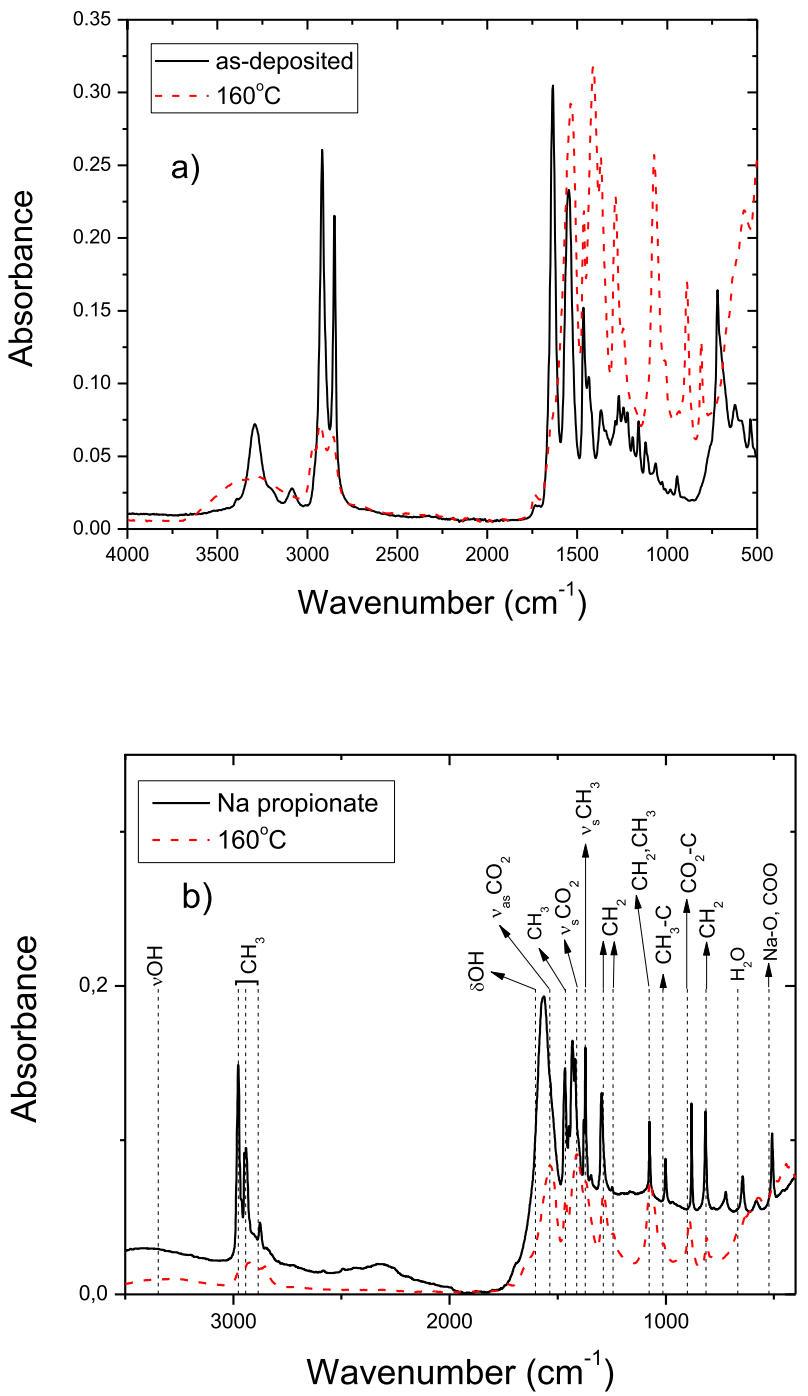

Fig. 4. a) FT-IR spectra of ceria deposit on PA12 before and after the decomposition at $10^{\circ} \mathrm{C} / \mathrm{min}$ from ambient temperature up to $160^{\circ} \mathrm{C}$ under a flowof $40 \mathrm{ml} / \mathrm{min}$ in synthetic air. b) Identification of the coating on PA12 by FT-IR after heating up to $160{ }^{\circ} \mathrm{C}$ in synthetic air by comparing it with sodium propionate.

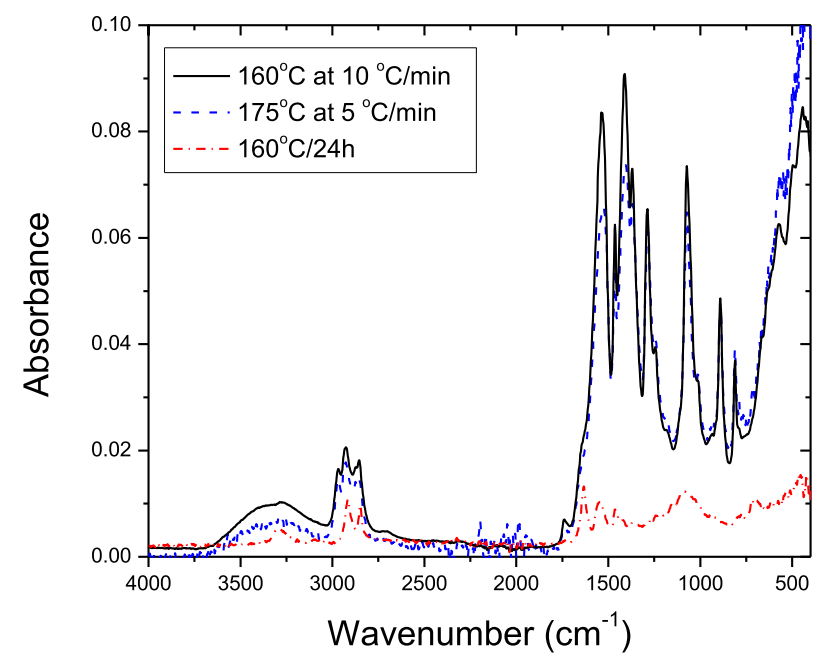

Fig. 5. FT-IR (ATR) of coated polyamide substrates heated in air at $160{ }^{\circ} \mathrm{C}$ and $175^{\circ} \mathrm{C}$ at 10 and $5^{\circ} \mathrm{C} / \mathrm{min}$, respectively, and kept at $160{ }^{\circ} \mathrm{C}$ for $24 \mathrm{~h}$.



Fig. 6. XRD of powders obtained on glass by a thermal treatment at $160^{\circ} \mathrm{C}$ for 6 days.

latter corresponds to a film kept in a muffle and is about 50-nm thick. As expected, the deposit at $175^{\circ} \mathrm{C}$ has a reduced signal compared to $160^{\circ} \mathrm{C}$, both due to higher temperature and slow ramp. Secondly, the deposit kept at $160^{\circ} \mathrm{C}$ for $24 \mathrm{~h}$ shows the most reduced signal, indicating that a large portion of the cerium propionate has indeed decomposed. Note that, as expected, the decomposition is significantly enhanced in the case of the thinner film. As a result, decomposition of the cerium propionate is demonstrated on the PA12 substrate.

Once the mechanism of the ink decomposition is known, a test of decomposition at $160^{\circ} \mathrm{C}$ for a long time of 6 days in air is undertaken on an inert substrate of glass to confirm if such a low temperature decomposition renders ceria and behaves similarly to the formulation described in [15]. XRD is shown in Fig. 6 where all reflections can be correctly assigned to the fluorite lattice of $\mathrm{CeO}_{2}$. The large breadth is an indication of the nanocrystalline size of the powders obtained at the low temperature of $160^{\circ} \mathrm{C}$.

To further check the presence of ceria, TEM was then performed, which is shown in Fig. 7. Large aggregates of nanoparticles are observed. When analyzed by electron diffraction, it gives almost continuous rings attributable to the diffraction of cubic ceria, in agreement

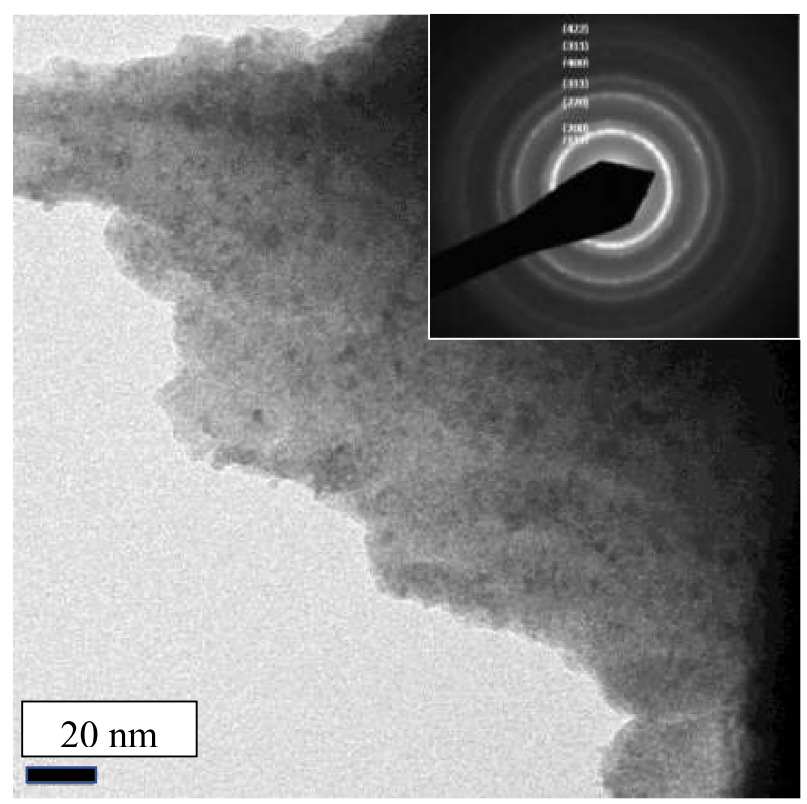

Fig. 7. TEM image and of powders on glass at $160{ }^{\circ} \mathrm{C}$ for 6 days. Indexed electron diffraction can be found in the insert. 


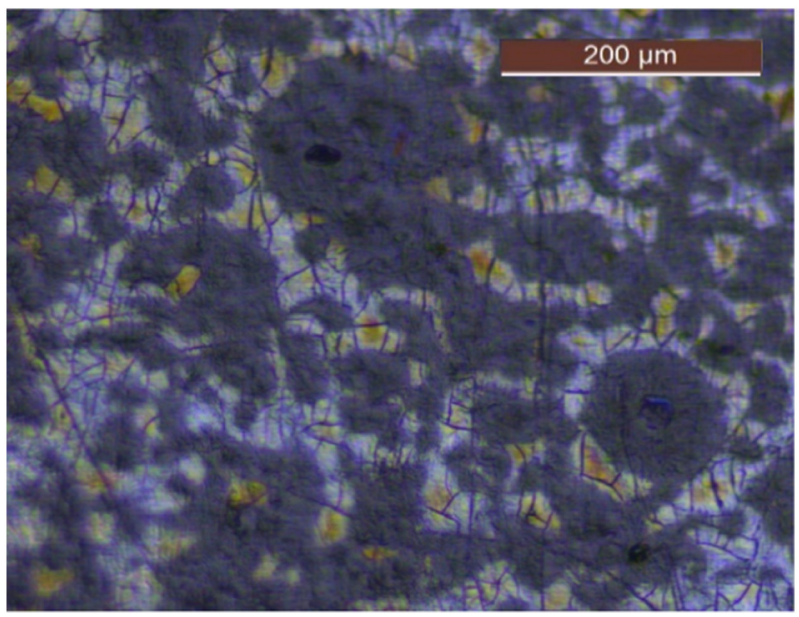

Fig. 8. Optical microscope image of deposit on PA12, treated at $160{ }^{\circ} \mathrm{C}$ for 6 days. Yellow and blue parts correspond to the ceria. (For interpretation of the references to colour in this figure legend, the reader is referred to the web version of this article.)

with powder diffraction in Fig. 6. Thus, formation of ceria from the precursor ink is confirmed at the low temperature of $160{ }^{\circ} \mathrm{C}$.

\subsection{Deposition on PA12}

After deposition by spin-coating with the ceria precursor ink and heating the coated piece of PA12 at $160^{\circ} \mathrm{C}$ for a long period of 6 days, the morphology of the deposit is shown in Fig. 8. The ceria can be clearly identified as the blue and yellow areas on the greyish PA12 surface. Thus, the ink does not wet the surface continuously but it suffers dewetting at some point after the supply of the ink. If it were a continuous layer, a thickness around $50 \mathrm{~nm}$ is estimated from the spinning conditions. Obviously, the dewetting makes the deposit thicker in the ceria regions and consequently, thickness can be larger. In fact, cracks are seen in the ceria areas likely because it exceeds critical thickness for crack-free layers, usually less than $1 \mu \mathrm{m}$, depending on a number of different parameters, such as the substrate, heating ramp or atmosphere [23].

In order to further confirm that cerium remained at the surface of the PA12, EDX was employed (Fig. 9) in which emission peaks from cerium are clearly observable.

To gain insight into the oxidation state of the deposits, XPS was

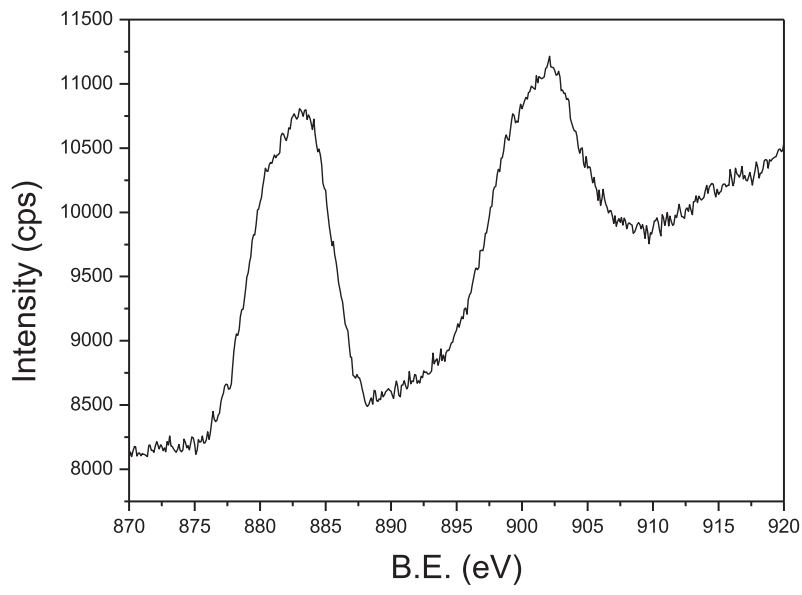

Fig. 10. XPS spectrum of sample treated at $160{ }^{\circ} \mathrm{C}$ for 6 days.

performed on this sample. The corresponding spectrum is plotted in Fig. 10, where two peaks at 883 and $902 \mathrm{eV}$ are prominent. Note that the $\mathrm{u}^{\text {" }}$ peak from $\mathrm{Ce}^{4+}$ at around $915 \mathrm{eV}$ is practically absent in our case. According to Zhang et al. [24], this result would be consistent with a thin layer of less of $10 \mathrm{~nm}$ typically of mostly $\mathrm{Ce}_{2} \mathrm{O}_{3}$, i.e. practically all cerium is in the $\mathrm{Ce}(\mathrm{III})$ oxidation state, although care should be taken that excessive reduction in the XPS chamber might take place.

On the other hand, no evidence for ceria crystallinity could be identified by XRD (Fig. 11). Only an increase of the reflections corresponding to the $\gamma$ phase of polyamide 12 [25] is registered owing to progressive crystallization of the polymer at $160^{\circ} \mathrm{C}$. Therefore, the lack of crystalline ceria indicates a very different behaviour with respect to inert substrates such as glass, where $\mathrm{CeO}_{2}$ nanoparticles were clearly observed by different techniques despite that long times were studied to allow for a potential better crystallization of the ceria nanoparticles.

One hypothesis to explain these experimental facts would be to conclude that polyamide cannot be considered as an inert substrate even at these low temperatures, as happens with glass or ceramic substrates. As commented above, polyamide slowly decomposes from $100{ }^{\circ} \mathrm{C}$ to produce $\mathrm{CO}$ and hydrocarbons. These reducing gases could react with the $\mathrm{Zr}$-doped cerium (IV) oxide to reduce it to $\mathrm{Ce}(\mathrm{III})$ oxide because both components are in close proximity. In fact, engineered ceria nanoparticles have shown catalytic behavior of this type at temperatures between 100 and $150^{\circ} \mathrm{C}$ compared to $250^{\circ} \mathrm{C}$ for the bulk phase [26]. Obviously, in an oxidizing atmosphere like air there is



Fig. 9. EDX analysis of a selected area of the coated substrate of PA after thermal treatment at $160{ }^{\circ} \mathrm{C} / 12 \mathrm{~h}$ showing signal from Ce. 




Fig. 11. XRD of the coated PA 12 treated at $160{ }^{\circ} \mathrm{C} / 24 \mathrm{~h}$ and pristine polymer for comparison purposes. All reflections can be attributed to the crystalline fraction of the PA12.

competition with oxygen gas for the oxidation of those gases at the surface level of the polyamide and, as a result, the actual redox scenario could be more complex. The fact that there is zirconium doping in our case could even enhance the catalytic performance as in [27].

Similar behavior as those reported in this work can be found in Shang et al.'s work [28] in which a metalorganic salt was introduced in a monomeric solution leading to a bulk polyimide $/ \mathrm{CeO}_{2}$ nanocomposite after polymerization at $300{ }^{\circ} \mathrm{C}$. However, in their case the $\mathrm{CeO}_{2}$ nanoparticles were inside the polymer and not at the surface. As in our case, X-ray diffraction and FT-IR were ineffective to show the crystallinity of ceria nanoparticles, being XPS the only technique successful in the identification of cerium.

\section{Conclusions}

An inkjet-compatible cerium (III) metalorganic solution was deposited on 3D-printed polyamide-12 flat substrates and heat treated at the low temperature of $160^{\circ} \mathrm{C}$ for different annealing times in order to preserve the base polymer as much as possible and attempting to form a functional ceria deposit at the same time. On all substrates studied, the ink transforms to cerium propionate which is decomposed progressively upon further heating. Although the ink was demonstrated to unambiguously convert to aggregates of $\mathrm{CeO}_{2}$ nanoparticles on glass, similar processing on the polyamide did not show evidences for crystallinity, being clearly detected by optical microscopy, XPS and EDX. Thus, the polyamide is concluded to be interacting with the coating, likely through the trace decomposition gases such as $\mathrm{CO}$ and hydrocarbons from the polymer below even at this low temperature.

More sophisticated characterization is thus required to identify the structure of the obtained cerium oxide like high-resolution TEM from focused-ion-beam-cut lamellae or high intensity microdiffraction of the coated areas.

\section{Acknowledgements}

This work was supported by Generalitat de Catalunya [2015 DI 029]. Guillaume Sauthier from Institut Català de Nanociència i Nanotecnologia (ICN2) is acknowledged for the XPS measurements.

\section{References}

[1] A. Trovarelli, P. Fornasiero, Catalysis by Ceria and Related Materials, second ed., Imperial College Press, London, 2013.

[2] N. Izu, W. Shin, N. Murayama, Fast response of resistive-type oxygen gas sensors based on nano-sized ceria powder, Sensors Actuators B Chem. 93 (2003) 449-453, https://doi.org/10.1016/S0925-4005(03)00167-9.

[3] B. Faure, G. Salazar-Alvarez, A. Ahniyaz, I. Villaluenga, G. Berriozabal, Y.R. De
Miguel, L. Bergström, Dispersion and surface functionalization of oxide nanoparticles for transparent photocatalytic and UV-protecting coatings and sunscreens, Sci. Technol. Adv. Mater. 14 (2013) 023001, , https://doi.org/10.1088/1468 6996/14/2/023001.

[4] Z. Li, J. Zhang, M. Li, X. Xing, Q. Zhang, Highly ordered macroporous-mesoporous $\mathrm{Ce}_{0.4} \mathrm{Zr}_{0.6} \mathrm{O}_{2}$ as dual-functional material in a polysulfide polymer, Nano Res. 11 (2018) 80-88, https://doi.org/10.1007/s12274-017-1607-2.

[5] X. Zhong, Q. Li, J. Hu, Y. Lu, Characterization and corrosion studies of ceria thin film based on fluorinated AZ91D magnesium alloy, Corros. Sci. 50 (2008) 2304-2309, https://doi.org/10.1016/j.corsci.2008.05.016.

[6] R.K. Singh, R. Bajaj, Advances in chemical-mechanical planarization, MRS Bull. 27 (2002) 743-751, https://doi.org/10.1557/mrs2002.244.

[7] Z. Li, W. Xue, B. Guan, F. Shi, Z. Shi, H. Jiang, C. Yan, A conceptual translation of homogeneous catalysis into heterogeneous catalysis: homogeneous-like heterogeneous gold nanoparticle catalyst induced by ceria supporter, Nanoscale 5 (2013) 1213-1220.

[8] T.G. Holesinger, S.R. Foltyn, P.N. Arendt, H. Kung, Q.X. Jia, R.M. Dickerson, P.C. Dowden, R.F. DePaula, J.R. Groves, J.Y. Coulter, The microstructure of continuously processed $\mathrm{YBa}_{2} \mathrm{Cu}_{3} \mathrm{O}_{\mathrm{y}}$ coated conductors with underlying $\mathrm{CeO}_{2}$ and ionbeam-assisted yttria-stabilized zirconia buffer layers, J. Mat. Res. 15 (2000) 1110-1119, https://doi.org/10.1557/JMR.2000.0158.

[9] M. Mogensen, N.M. Sammes, G.A. Tompsett, Physical, chemical and electrochemical properties of pure and doped ceria, Solid State Ionics 129 (2000) 63-94, https://doi.org/10.1016/S0167-2738(99)00318-5.

[10] J. Minguella-Canela, S. Morales-Planas, J.R. Gomà-Ayats, M.A. de los Santos-López, Assessment of the potential economic impact of the use of AM technologies in the cost levels of manufacturing and stocking of spare part products, Materials 11 (2018) 1429, https://doi.org/10.3390/ma11081429.

[11] S. Morales-Planas, J. Minguella-Canela, J. Lluma-Fuentes, J.A. Travieso-Rodriguez, A.A. García-Granada, Multi Jet Fusion PA12 manufacturing parameters for watertightness, strength and Tolerances, Materials 11 (2018) 1472, https://doi.org/10. $3390 /$ ma11081472.

[12] H. Li, G. Wang, F. Zhang, Y. Cai, Y. Wang, I. Djerdj, Surfactant-assisted synthesis of $\mathrm{CeO}_{2}$ nanoparticles and their application in wastewater treatment, RSC Adv. 2 (2012) 12413-12423, https://doi.org/10.1039/c2ra21590j.

[13] P. Janos, P. Kuran, M. Kormunda, V. Stengl, T.M. Grygar, M. Dosek, M. Stastny, J. Ederer, V. Pilarova, L. Vrtoch, Cerium dioxide as a new reactive sorbent for fast degradation of parathion methyl and some other organophosphates, J. Rare Earth 32 (2014) 360-370, https://doi.org/10.1016/S1002-0721(14)60079-X.

[14] J. Perelaer, P.J. Smith, D. Mager, D. Soltman, S.K. Volkman, V. Subramanian, J.G. Korvinkdf, U.S. Schubert, Printed electronics: the challenges involved in printing devices, interconnects, and contacts based on inorganic materials, J. Mater. Chem. 20 (2010) 8446-8453, https://doi.org/10.1039/c0jm00264j.

[15] P. Roura, J. Farjas, S. Ricart, M. Aklalouch, R. Guzman, J. Arbiol, T. Puig, A. Calleja O. Peña-Rodríguez, M. Garriga, X. Obradors, Synthesis of nanocrystalline ceria thin films by low-temperature thermal decomposition of Ce-propionate, Thin Solid Films 520 (2012) 1949-1953, https://doi.org/10.1016/j.tsf.2011.09.058.

[16] D. Sanchez-Rodriguez, J. Farjas, P. Roura, S. Ricart, N. Mestres, X. Obradors, T. Puig, Thermal analysis for low temperature synthesis of oxide thin films from chemical solutions, J. Phys. Chem. C 117 (2013) 20133-20138, https://doi.org/10. 1021/jp4049742.

[17] P. Roura, J. Farjas, H. Eloussi, L. Carreras, S. Ricart, T. Puig, X. Obradors, Thermal analysis of metal organic precursors for functional oxide preparation: thin films versus powders, Thermochim. Acta 601 (2015) 1-8, https://doi.org/10.1016/j.tca. 2014.12.016.

[18] B.G. Achhammer, F.W. Reinhart, G.M. Kline, Mechanism of the degradation of polyamides, J. Appl. Chem. 1 (1951) 301-319, https://doi.org/10.1002/jctb. 5010010704.

[19] M. Herrera, G. Matuschek, A. Kettrup, Main products and kinetics of the thermal degradation of polyamides, Chemosphere 42 (2001) 601-607, https://doi.org/10. 1016/S0045-6535(00)00233-2.

[20] F. Selampinar, U. Akbulut, T. Yalqin, S. Süzer, L. Toppare, A conducting composite of polypyrrole I. synthesis and characterization, Synth. Met. 62 (1994) 201-206, https://doi.org/10.1016/0379-6779(94)90206-2.

[21] S. Rasi, S. Ricart, X. Obradors, T. Puig, P. Roura, J. Farjas, Thermal decomposition of yttrium propionate: film and powder, J. Anal. Appl. Pyrolysis 133 (2018) 225-233, https://doi.org/10.1016/j.jaap.2018.03.021.

[22] M. Kakihana, T. Nagumo, Assignment for the infrared Spectrum of solid sodium propionate from low-temperature measurements in combination with $13 \mathrm{C}$ isotopic shifts, Zeitschrift Für Naturforsch. A. 42 (1987) 477-484, https://doi.org/10.1515/ zna-1987-0509.

[23] A. Atkinson, R.M. Guppy, Mechanical stability of sol-gel films, J. Mater. Sci. 26 (1991) 3869-3873, https://doi.org/10.1007/BF01184984.

[24] F. Zhang, P. Wang, J. Koberstein, S. Khalid, S.W. Chan, Cerium oxidation state in ceria nanoparticles studied with X-ray photoelectron spectroscopy and absorption near edge spectroscopy, Surf. Sci. 563 (2004) 74-82, https://doi.org/10.1016/j. susc. 2004.05.138.

[25] T. Ishikawa, S. Nagai, Effect of casting conditions on polymorphism of nylon-12, J. Polym. Sci. B Polym. Phys. 11 (1973) 1077-1089, https://doi.org/10.1002/pol. 1980.180180212.

[26] N.J. Lawrence, J.R. Brewer, L. Wang, T.S. Wu, J. Wells-Kingsbury, M.M. Ihrig, G. Wang, Y.L. Soo, W.N. Mei, C.L. Cheung, Defect engineering in cubic cerium oxide nanostructures for catalytic oxidation, Nano Lett. 11 (2011) 2666-2671, https:// doi.org/10.1021/nl200722z.

[27] H. Kaneko, S. Taku, Y. Tamaura, Reduction reactivity of $\mathrm{CeO}_{2}-\mathrm{ZrO}_{2}$ oxide under high $\mathrm{O}_{2}$ partial pressure in two-step water splitting process, Sol. Energy 85 (2011) 2321-2330, https://doi.org/10.1016/j.solener.2011.06.019.

[28] Z. Shang, C. Lu, X. Lu, L. Gao, Studies on syntheses and properties of novel $\mathrm{CeO}_{2} /$ polyimide nanocomposite films from Ce(Phen) $)_{3}$ complex, Polymer 48 (2007) 4041-4046, https://doi.org/10.1016/j.polymer.2007.03.077. 